\title{
A STUDY OF IMPACT OF WATCHING TV ON SOCIETY USING ON STATISTICAL TOOLS AND TECHNIQUES
}

\author{
Prakash S. Chougule ${ }^{1}$ \\ ${ }^{1}$ Associate Professor, \\ Rajarshi Chhatrapati Shahu College, \\ Kolhapur(MS), \\ India \\ S. V.Patil ${ }^{3}$ \\ ${ }^{3}$ Associate Professor, \\ Rajarshi Chhatrapati Shahu College, \\ Kolhapur(MS), \\ India \\ Prakash S. Kolapate ${ }^{5}$ \\ ${ }^{5}$ Research Student, \\ Rajarshi Chhatrapati Shahu College, \\ Kolhapur(MS), \\ India
}

\author{
Tejaswi S.Kurane ${ }^{2}$ \\ ${ }^{2}$ Assistant Professor, \\ Rajarshi Chhatrapati Shahu College, \\ Kolhapur(MS), \\ India
}

\author{
Arati R. Todakar ${ }^{4}$ \\ ${ }^{4}$ Research Student, \\ Rajarshi Chhatrapati Shahu College, \\ Kolhapur(MS), \\ India
}

\author{
Gouri S. Patole ${ }^{6}$ \\ ${ }^{6}$ Research Student, \\ Rajarshi Chhatrapati Shahu College, \\ Kolhapur(MS), \\ India
}

\begin{abstract}
Twenty first century has seen rapid technological advancement in mass media. Among all mass media, television is an important and an unavoidable thing. It is a window to the world.In this study we want see what is the influence of watching T.V. on society for this purpose we collect the primary information through systematic questionnaires contained number of attributes like gender,area, age group,expenditure etc.the collected data is analysed through various statistical measures.our study shows that the proportion of watching $T . V$. in urban area is high as compared to rural area and maximum number of individuals of watching TV is in the age group 20-40.
\end{abstract}

KEYWORDS: Graphical Representation, chis-quare Test, ANOVA, Level of significance.

\section{INTRODUCTION}

Twenty first century has seen quick mechanical headway in broad communications. Among all broad communications, TV is a significant and an unavoidable thing. It is a "window to the world". All out number of TV homes in India would be in excess of 100 million. The metropolitan provincial proportion of TV homes is expanding In India, before the appearance of $\mathrm{TV}$, film and radio were extremely well known. At first, the TV was presented in 1959 as an instrument of correspondence. Afterward, it turned into an amusement medium. Presently it has been accessible in every single family in India. The presentation of satellite TV in 1991 drastically changed the survey example of our kin. As of now, we have umpteen number of western, Indian, provincial, nearby and Govt. TV stations (Dr. Dhyan Singh). It is an incredible medium and go about as an impetus of social change. TV has changed our planet into a "immense electronic town" bringing all individuals and nations close (Bushan 1992).As of late, numerous specialists have demonstrated revenue as to TV's effect on human lives at any phase of 
improvement. On account of its joined general media impacts, it has been considered as a conceivably solid specialist for youngsters and youths. Youthful watchers stare at the TV as a method of pie in the sky ID and hence, favor TV depictions (Boehnke, Munch and Hoffman, 2002). It is presently demonstrated that TV can profoundly affect kids and youths' turn of events and conduct.

Kubey and Csikszentmihaly (1990) have detailed that TV seeing is by all accounts a uninvolved movement and that necessary little focus on their part when contrasted with assortment of other recreation time exercises. TV seeing appears to have kept up its prevailing situation in the present youth recreation time. In spite of the fact that the presentation of PCs and the web appears to have definitely adjusted home admittance to media diversion, still TV keeps on convincing kids to dedicate significant part of their chance to its programming (Roberts, 2000 and Koolstra, 1999). Parker (1961) has set up that TV has extensively diminished an opportunity to be spent for different exercises. We know that recently the competition is increased in every field of life. Therefore the students should get the ability to compete the world. We know that every year 6.8 crores students complete their graduation in India. But how many of them are getting a good settled life is a more important question. Here we introduced the students time with their TV. All these things of consistency in their watching TV should benefit to get the knowledge. So this study gives an idea about the spending time with TV of students and teachers. In this article we studied the comparative with area as well as gender of students and teachers. We introduced the area wise separation of students and teachers for watching TV with gender. We also study the effect of TV in human mind.In 6 colleges we take 159 peoples in which 121 students and 38 teachers. We have collected their information in the form of primary data.

\section{OBJECTIVES}

$>$ To test whether the correlation coefficient between age and time is correlated or uncorrelated.

$>$ To test whether the correlation coefficient between age and time is correlated or uncorrelated.

$>$ To test whether the different stages of a day are independent on working \& non-working days for watching TV in urban area.

$>$ To test whether the different stages of a day are independent on working \& non-working days for watching TV in rural area.

$>$ To test whether the education level is independent on different area.

$>$ To tests whether the availability of television is independent on different

$>$ To analysis of CRD for given data.

\section{METHODOLOGY}

For collection of data we use questionnaires and the questionnaires includes the information about their address, use of phone, marks, parent occupation and annual income, family and also their view about teachers performance. We collect information of 121 students and 38 teachers from Science faculty.Primary data collected from following three groups accordingly T.Y. B.Sc.,S.Y. B.Sc. students and Teachers

\section{Statistical tools}

1. Graphical representation.

2. Testing of hypothesis.

3. Test for correlation coefficient.

4. One way ANOVA.

\section{Software Used}

1. MS-Excel

\section{GRAPHICAL REPRESENTATION}

\begin{tabular}{|c|c|}
\hline Age group & No. of individuals \\
\hline Below 20 & 65 \\
\hline $20-40$ & 74 \\
\hline Above 40 & 20 \\
\hline
\end{tabular}

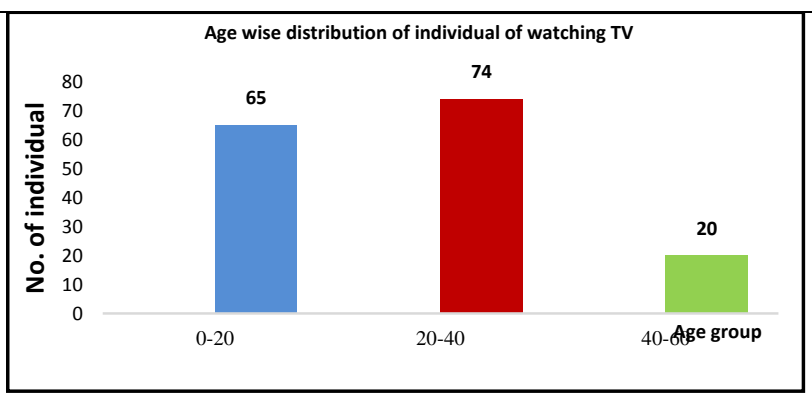




\begin{tabular}{|c|c|c|}
\hline \multicolumn{2}{|c|}{ Area } & No. of individuals \\
\hline \multirow{3}{*}{ Rural } & Yes & 69 \\
\cline { 2 - 3 } & No & 6 \\
\hline \multirow{3}{*}{ Urban } & Yes & 80 \\
\cline { 2 - 3 } & No & 4 \\
\hline
\end{tabular}

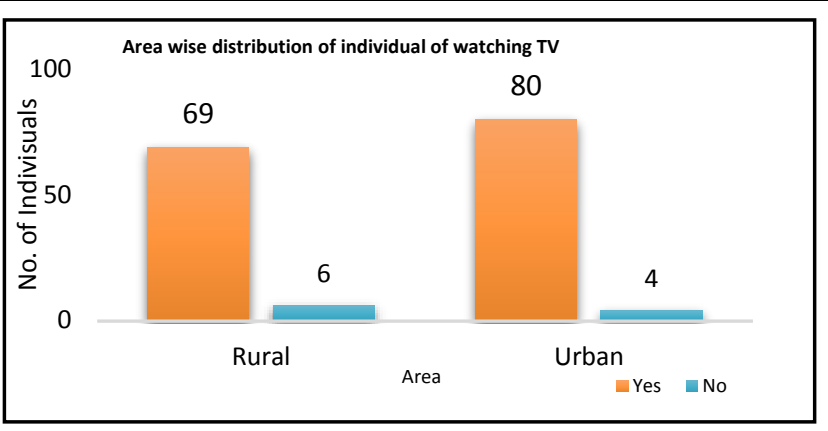

\begin{tabular}{|l|c|c|}
\hline Expenditure/Area & Rural & Urban \\
\hline Food & 184000 & 333600 \\
\hline Clothing & 108300 & 158600 \\
\hline Housing & 152800 & 257500 \\
\hline Education & 163900 & 252700 \\
\hline Medicine & 79100 & 108880 \\
\hline Entertainment & 78700 & 78700 \\
\hline Other & 130000 & 414700 \\
\hline
\end{tabular}

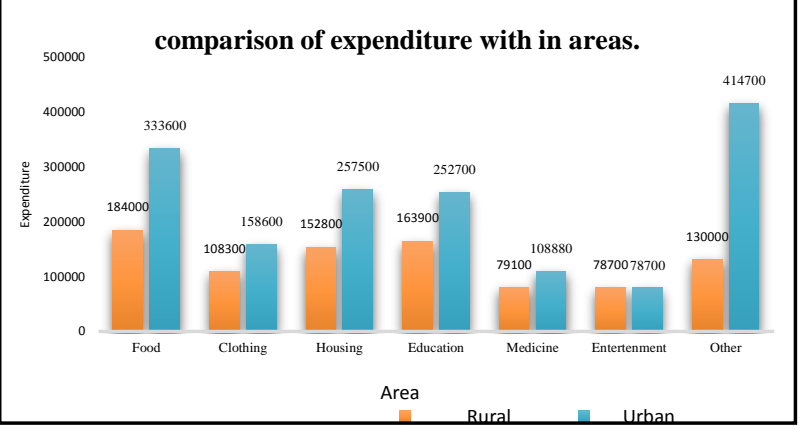

\begin{tabular}{|l|c|c|}
\hline Types of TV & Rural & Urban \\
\hline LCD & 10 & 25 \\
\hline LED & 5 & 15 \\
\hline Black \& White & 0 & 02 \\
\hline Colour & 47 & 43 \\
\hline Total & 62 & 85 \\
\hline
\end{tabular}

\begin{tabular}{|l|l|}
\hline $\begin{array}{l}\text { Type of Effect on Human } \\
\text { mind }\end{array}$ & $\begin{array}{l}\text { No. of } \\
\text { Persons }\end{array}$ \\
\hline Positive & 87 \\
\hline Negative & 22 \\
\hline Both & 10 \\
\hline None of these & 40 \\
\hline
\end{tabular}
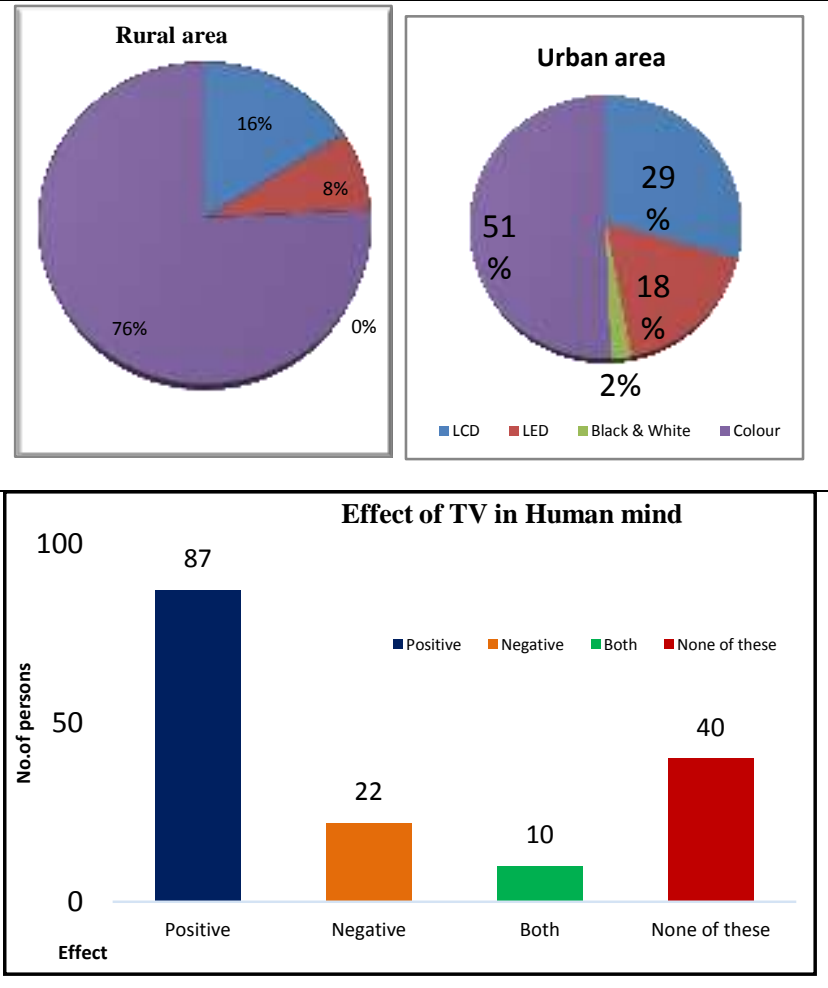

\section{TESTING OF HYPOTHESIS}

a) Chisquare test for independency of age wise watching TV in areas:

Let the hypothesis are stated as

$\mathrm{H}_{0}$ : Watching TV is independent on areas. v/s $\mathrm{H}_{1}$ : Watching TV is dependent on areas.

Level of significance: $\quad=\alpha \%=5 \%$ 


\section{Test Statistics}

$$
\chi^{2}=\frac{N\left[|a d-b c|-\frac{N}{2}\right]^{2}}{(a+b)(a+c)(c+d)(b+d)} \sim \chi 2_{1}
$$

\section{Observation table}

\section{Calculation}

\begin{tabular}{|l|l|l|l|}
\hline \multirow{2}{*}{ Area } & \multicolumn{2}{|c|}{$\begin{array}{c}\text { Watching } \\
\text { TV }\end{array}$} & \multirow{2}{*}{ Total } \\
\cline { 2 - 4 } & Yes & No & \\
\hline Rural & 82 & 2 & 84 \\
\hline Urban & 73 & 2 & 75 \\
\hline Total & 155 & 4 & 159 \\
\hline
\end{tabular}

$$
\begin{aligned}
\chi^{2} & =\frac{N\left[|a d-b c|-\frac{N}{2}\right]^{2}}{(a+b)(a+c)(c+d)(b+d)} \sim \chi^{2}{ }_{1} \\
& =0.1539 \\
\chi^{2} \text { tab } & =\chi^{2}{ }_{1} \\
& =3.841
\end{aligned}
$$

\section{b) Chisquare test for independence of education level in areas}

\section{Hypothes is:}

$\mathrm{H}_{0}$ : Education level is independent on areas. $\mathrm{v} / \mathrm{s} \mathrm{H}_{1}$ : Education level is dependent on areas. Level of significance $=\alpha \%=5 \%$

\section{Test Statistics}

$$
\chi^{2}=\frac{N\left[|a d-b c|-\frac{N}{2}\right]^{2}}{(a+b)(a+c)(c+d)(b+d)} \sim \chi 2_{1}
$$

\section{Observation table}

\begin{tabular}{|c|c|c|c|}
\hline \multirow{2}{*}{ Area } & \multicolumn{2}{|c|}{ Education level } & \multirow{2}{*}{ Total } \\
\cline { 2 - 3 } & U.G. & P.G. & \\
\hline Rural & 58 & 22 & 80 \\
\hline Urban & 46 & 33 & 79 \\
\hline Total & 104 & 55 & 159 \\
\hline
\end{tabular}




\section{Calculation}

$\chi^{2}=\frac{N[a d-b c]^{2}}{(a+b)(a+c)(c+d)(b+d)}$
$=4.0896$
Degrees of freedom $=(\mathrm{r}-1)^{*}(\mathrm{c}-1)$
$=(2-1)(2-1)=1$
$\chi_{\mathrm{tab}}^{2}=3.576$.

C) Chi-square test test for independency in different stages of a day and working and nonworking days of watching TV in Rural area:

\section{Hypothesis}

$\mathrm{H}_{0}$ : The different stages of day are independent on working \& non-working days for watching TV. V/s

$\mathrm{H}_{1}$ : The different stages of day are dependent on working \& non-working days for watching TV.

Test statistics : $\quad \chi^{2}=\frac{(O i-E i)^{2}}{E i}$

Level of significance : $\quad \alpha \%=5 \%$

\section{Observation Table}

\begin{tabular}{|c|c|c|c|}
\hline & $\begin{array}{c}\text { Working } \\
\text { day }\end{array}$ & $\begin{array}{c}\text { Non- } \\
\text { Working } \\
\text { day }\end{array}$ & Total \\
\hline Morning & 0 & 14 & 14 \\
\hline Afternoon & 4 & 18 & 22 \\
\hline Evening & 22 & 14 & 36 \\
\hline Night & 41 & 30 & 71 \\
\hline Total & 67 & 76 & 143 \\
\hline
\end{tabular}

\section{Calculation}

\begin{tabular}{|l}
$\sum \frac{(O i-E i)^{2}}{E i}=25.9424$ \\
$\chi^{2}=15.7341$ \\
$\chi^{2}=\chi^{2}=$
\end{tabular}

d) Chi-square test test for independency in different stages of a day and working and non-working days of watching $\mathrm{TV}$ in Rural area

\section{Hypothesis}

$\mathrm{H}_{0}$ : The different stages of day are independent on working \& non-working days for watching TV.

$\mathrm{H}_{1}$ : The different stages of day are dependent on working \& non-working days for watching TV. 


\section{Observation Table}

\begin{tabular}{|l|c|c|c|}
\hline & Working day & Non-Working day & Total \\
\hline Morning & 4 & 12 & 16 \\
\hline Afternoon & 2 & 28 & 30 \\
\hline Evening & 21 & 19 & 40 \\
\hline Night & 41 & 29 & 78 \\
\hline Total & 76 & 88 & 164 \\
\hline
\end{tabular}

\section{Calculation}

$$
\begin{aligned}
& \text { Here }, \\
& \chi^{2} \text { cal }=31.0496 \\
& \chi^{2} \text { tab }=7.815
\end{aligned}
$$

\section{One way ANOVA:}

\section{Hypothesis}

$\mathrm{H}_{0}$ : The average of time (in min.) by permanent, temporary, full time, part time is not equal

$\mathrm{H}_{1}$ : The average of time (in min.) by permanent, temporary, full time, part time is equal.

\section{Calculation}

\begin{tabular}{|c|c|c|c|c|c|}
\hline & Sum of Square & $\begin{array}{l}\text { Degrees of } \\
\text { freedom }\end{array}$ & $\begin{array}{c}\text { Mean Sum of } \\
\text { square }\end{array}$ & F- ratio & $\begin{array}{c}F_{\text {tab }}= \\
F_{(3,66)}=\end{array}$ \\
\hline Between Groups & 11969.84 & 3 & 3989.948 & 1.454185 & 2.64 \\
\hline Within Groups & 181088.7 & 66 & 2743.769 & & \\
\hline Total & 193058.6 & 69 & & & \\
\hline
\end{tabular}

$$
\begin{aligned}
& \mathrm{G}=6080 ; \text { C.F. }=535744.9275 ; \mathrm{TSS}=193058.6 ; \mathrm{SSTr}=11969.84 \\
& \mathrm{SSE}=181088.7 ; \mathrm{s}_{\mathrm{tr}}=3989.948 ; \mathrm{s}_{\mathrm{e}}{ }_{\mathrm{e}}=2343.769
\end{aligned}
$$

ANOVA TABLE

\section{CONCLUSION}

From our study we conclude that many students watch TV for long time and maximum number of individuals of watching TV is in the age group 20-40, also observed that number of individual of watching TV is in urban area is more than rural area.The expenditure of individuals from rural area is less as compared to that of urban area but in case of entertainment, the expenditure of individuals from both the area is approximatley same. The more use of colour TV in urban area than rural area. age wise population watching TV in areas are independent also education level is independent on areas.we conclude that the different stages of day are dependent on working \& non-working days for watching TV in rural areas well as in urban area .According to one way ANOVA test, the average of time by permanent, temporary, full time, part time is not equal.

\section{BIBLIOGRAPHY}

1. Bushan, C. (1992): Educational Communication By Television. Bharatia Skikshan. Vol.2, No.8. Bombay: S. Cmela Mergh.

2. Boehnke, K., Munch, T\& Hoffmann, D. (2002): Development through media use? A German study on 
the use of radio in adolescence. International Journal of behavioral Development. Vol. 26, Pp.193201.

3. Kubey and Csikszentmihaly (1990): Television use in everyday life: Coping with unstructured time. Journal of Communication. Vol.36,Pp. 108-123.

4. Koolstra, C. (1999): Longitudinal effects of television on children's leisure time reading: A test of three explanatory models. Human communication Research, Vol. 23, Pp. 4-35.

5. Roberts, D. F. (2000). Media and youth: Access, exposure, and privatization. Journal of Adolescent Health, Vol.27(2):Pp.8-14.

6. Schramm, W., Lyle, J., Parker, E. B., 1961.Television in the lives of our children. Stanford University Press, Stanford. 